\title{
Doctors back BMA's refusal to join debate on assisted dying
}

This news article by Nigel Hawkes (BMJ 2011;343:d4188, doi:10.1136/bmj.d4188) attributed the quote in the final paragraph ("It's not fair at all to say that $B M J$ has been biased") to Hamish Meldrum, whereas in fact it came from Tony Calland. 